"Volume 10, No. 2, Desember 2016"

\title{
RELIGIOUS ENVIRONMENT: Penciptaan Suasana Religius di Sekolah
}

\author{
Oleh: \\ Minhaji \& Nurul Qomariyah \\ Fakultas Tarbiyah IAI Ibrahimy Situbondo \\ moh_minhaji@yahoo.co.id \& enqiu90@gmail.com
}

\begin{abstract}
Religious Education is a field of study that must be given to students at each level of education, where implementation has become a national commitment, so its presence becomes an absolute element in the moral formation of the Indonesian nation. There have been many deviation and moral degradation, as a result of the development of science and technology education.Thereforeneed to be applied in view of Islamic education to the creation of a religious atmosphere in the school environment that is not enough to do in the classroom.

The creation of a religious atmosphere in the school is very urgent to implemented. Because that processisthe process of spiritual upliftment and creation of learner's faith tosubmit to God Almighty andalso noble characters.Noble characters include moral cultivation as the realization of the purpose of Islamic education.
\end{abstract}

Keywords: Creation, Religious dan Atmosphere

\section{A. Pendahuluan}

Budaya religius di lingkungan sekolah merupakan salah satu metode pendidikan nilai yang komprehensif. Karena dalam perwujudannya terdapat internalisasi nilai, pemberian teladan, pembentukan moral melalui metode pembiasaan (habit) kepada warga sekolah. Hal ini merupakan bentuk reformasi pendidikan agama islam yang berangkat dari konsep revitalisasi pendidikan agama islam yang sudah lama menjadi kebutuhan umat islam di dunia. ${ }^{1}$

Dunia pendidikan di Indonesia saat ini mulai diresahkan dengan merebaknya paham hedonisme. ${ }^{2}$ Dampak dari kehidupan yang hedonistik ini sudah demikian parah, karena semakin didukung oleh keberhasilan

\footnotetext{
${ }^{1}$ Ahmad Arifi, Politik Pendidikan Islam: Menelisuri Ideologi dan Aktualisasi Pendidikan Islam di Tengah Arus Globalisasi, (Yogyakarta: Teras, 2010), cet.ke-1, hlm. 142.

2 Hedonisme yaitu suatu pandangan hidup yang menganggap bahwa kesenangan dan kenikmatan (kelezatan) materi adalah tujuan utama hidup.
} 
pembangunan bidang material yang kurang seimbang dengan pembangunan bidang spiritual dan moral. ${ }^{3}$ Pandangan hidup yang seperti ini akan memberikan corak dalam berfikir, bersikap, berprilaku dan gaya hidup yang akan teraplikasi dalam kehidupan sehari-hari. Maka dari itu dibutuhkan pendidikan yang mencakup dua unsur utama, yaitu pendidikan yang tidak hanya menjunjung tinggi keberhasilan akademik, namun juga keberhasilan nonakademik (termasuk keunggulan spiritual), keduanya harus berjalan seirama dan selaras.

Gerakan pendidikan yang berjalan seirama tersebut sesuai dengan tujuan pendidikan nasional yang tertuang di dalam Undang-Undang SISDIKNAS No. 20 Tahun 2003 BAB II pasal 3 yakni:

“... Bertujuan untuk berkembangnya potensi peserta didik agar menjadi manusia yang beriman kepada Tuhan Yang Maha Esa, berakhlaq mulia, berilmu, cakap, kreatif, mandiri dan menjadi warga negara yang demokratis, serta bertanggungjawab."4

Seiring dengan tujuan pendidikan nasional yang menyelaraskan antara kedua unsur utama di atas, dibutuhkan lembaga pendidikan yang mampu mewadahi kebutuhan masyarakat tersebut. Sekolah sebagai lembaga pendidikan formal berupaya menjawab tantangan globalisasi tersebut. Sebagaimana realita yang penulis temui disalah satu lembaga pendidikan yang bonavit di Kabupaten Situbondo, tepatnya berada di kecamatan kawasan timur Kota yang terkenal dengan nama SMP Negeri 1 Asembagus. Lembaga pendidikan formal yang terletak di kawasan yang terkenal dengan sebutan The Second City ini, terkenal dengan visi misinya yakni mencetak generasi yang BERSINAR (Berakhlaq, Smart Iptek, Natural dan Religius).

SMP Negeri 1 Asembagus berupaya merevitalisasi aktivitas keagamaan peserta didik melalui berbagai aktivitas-aktivitas keagamaan yang diprogramkan, dan mengintegrasikan nilai-nilai pendidikan agama Islam ke dalam aktivitas sehari-hari, dalam kata lain membiasakan peserta didik mengerjakan aktivitas keagamaan, sehingga lama kelamaan akan tumbuh rasa senang melakukan ibadah. ${ }^{5}$ Sesuai dengan tujuan

3 Abudin Nata, Akhlak Tasawuf dan Karakter Mulia edisi revisi, (Jakarta: Raja Grafinda Persada, 2013), hlm. 93.

4 Undang-Undang Republik Indonesia No.20 Tahun 2003 tentang Sistem Pendidikan Nasional, (Jakarta: Sinar Grafika, 2008), hlm. 6.

5 Hasil Observasi awal penulis di SMP Negeri 1 Asembagus, pada tanggal 27 November 2015

$232 \mid$ JURNAL LISAN AL-HAL 
Pendidikan Agama Islam yang dikemukakan oleh Pusat Kurikulum Depdiknas yakni: 6

"Bertujuan untuk menumbuhkan dan meningkatkan keimanan peserta didik melalui pembenaran dan pemupukan pengetahuan, penghayatan, pengamalan, serta pengalaman peserta didik tentang agama islam sehingga menjadi manusia muslim yang terus berkembang dalam hal keimanan, ketakwaan kepada Allah SWT serta berakhlaq mulia di dalam kehidupan pribadi, bermasyarakat, berbangsa dan bernegara."

Dari serentetan uraian tujuan Pendidikan Agama Islam di atas, pada kalimat "pengalaman peserta didik tentang agama Islam", nampak jelas bahwasanya peserta didik tidak hanya disuapi dengan teori saja melainkan pendidikan seharusnya juga menyuguhkan prakteknya langsung dilapangan. Peserta didik dibiasakan mengenal dan mengamalkan ajaran agama Islam sejak dini, karena dengan menanamkan kebiasaan (habit) kepada mereka, peserta didik akan memiliki pemahaman yang tinggi dan kesadaran, serta kepedulian dan komitmen untuk diterapkan dalam kehidupan sehari-hari. ${ }^{7}$ Jika demikian, maka sekolah sebagai lembaga pendidikan formal telah mampu mengemban amanat nasional yang bertendensi pada keselarasan dua unsur utama tadi. Alhasil, tujuan pendidikan nasional yang dicita-citakan akan tercapai. Sebagaimana yang dipaparkan oleh Waka. Kurikulum dihadapan seluruh siswa dan jajaran guru SMP Negeri 1 Asembagus, saat memberikan arahan ketika menjadi pembina upacara, beliau mengingatkan kita bahwasanya: ${ }^{8}$

"Apa yang kita lakukan saat ini, gantungkan semuanya kepada Allah SWT, dan lakukanlah semuanya karena Allah, karena segala perbuatan akan siasia jika tidak dilandasi niat karena Allah, teruslah tingkatkan ibadah kita kepada-Nya, bukan hanya Ipteknya saja, akan tetapi spiritualnya juga mantap, banyak orang pintar tapi spiritualnya nol, buat apa? Bukan tujuan hidup, tetapi padukan keduanya agar menjadi muslim yang BERSINAR". ${ }^{9}$

Sebagaimana firman Allah SWT di dalam Al-Qur'an sebagai berikut:

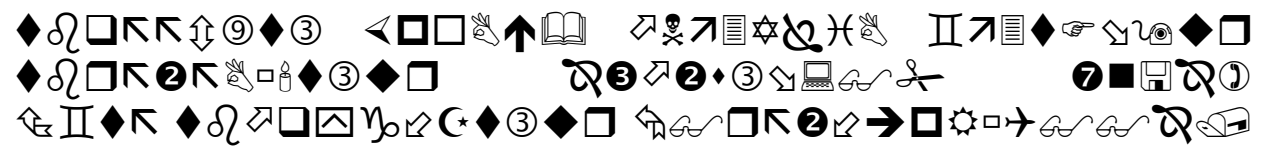

6 A. Munjin Nasih dan Lilik NK, Metodologi Pembelajaran Pendidikan Agama Islam, (Malang: Cakrawala Indonesia, 2009), 7.

7 Abudin Nata, Akhlak Tasawuf dan Karakter Mulia edisi revisi, (Jakarta: Raja Grafinda Persada, 2013), 316.

8 Observasi Peneliti pada saat upacara bendera berlangsung, hari senin, 30 November 2015, jam 06:45 WIB di lapangan SMP Negeri 1 Asembagus.

9 Berakhlaq, Smart Iptek, Natural dan Religius 


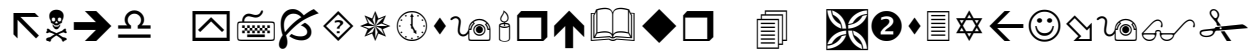

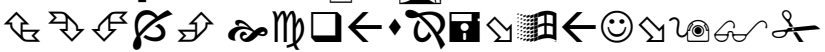

"Dan hendaklah ada di antara kamu segolongan umat yang menyeru kepada kebajikan, menyuruh kepada yang ma'ruf dan mencegah dari yang munkar dan merekalah orang-orang yang beruntung" (Q.S Ali-Imron: 104). ${ }^{10}$

Dalam hal meningkatkan perkembangan diri siswa ke arah yang baik, tidak hanya dari dalam diri siswa itu sendiri, akan tapi faktor lingkungan juga mempengaruhi. Karena pada dasarnya, faktor yang mempengaruhi tinggi rendahnya mutu perkembangan siswa terdiri dari dua macam, yaitu: ${ }^{11}$ Pertama, faktor Intern, yaitu faktor yang ada dari dalam diri siswa itu sendiri, seperti motivasi diri. Kedua, faktor Ekstern, yaitu faktor yang datang dari luar diri siswa, seperti lingkungan (khususnya pendidikan), dan pengalaman siswa tersebut berinteraksi dengan lingkungannya.

Kepala sekolah mempunyai peranan penting dalam pengembangan lembaga pendidikan untuk meningkatkan kualitas proses pendidikan. Untuk itu sekolah diharapkan memiliki program khusus untuk meningkatkan kualitas keberagamaan. Salah satu upaya SMP Negeri 1 Asembagus, yaitu menciptakan suasana religius di lingkungan sekolah. Diantaranaya seperti shalat berjama'ah dzuhur, shalat dhuha, jum'at beramal, $3 \mathrm{~S}$ (Senyum, Sapa, Salam), dan juga program religi yang baru saja diresmikan, dan bekerja sama dengan pondok pesantren Salafiyah Syafi'iyah Sukorejo-Situbondo, yakni "Pesantren Sekolah", yang diisi dengan fokus pembelajaran Al-Qur'an baik hafalan, membaca, dan juga pemahaman tentang Al-Qur'an. ${ }^{12}$ Dalam pembagiannya peserta didik di klasifikasikan kebeberapa kelompok belajar, dari tingkatan dasar, menengah sampai tingkat atas, jadi sebelumnya sudah dilakukan penyaringan atau penyeleksian sesuai dengan kemampuannya dalam membaca Al-Qur'an.

Adapun yang menjadi fokus persoalan dan sekaligus tujuan yang ingin dicapai dalam penulisan ini adalah untuk mengetahui penerapan penciptaan suasana religius di SMP Negeri 1 Asembagus- Situbondo.

10 al- Qur'an, 3:104.

11 Muhibbin Syah, Psikologi Pendidikan Dengan Pendekatan Baru, (Bandung: PT Remaja Rosdakarya, 2013), cet.ke-18, hlm. 47.

12 Jawa Pos Radar Situbondo, Tanamkan Sikap Religius Melalui Pesantren Sekolah, (Sabtu, 28 November 2015), hlm. 35.

$234 \mid$ JURNAL LISAN AL-HAL 
Sedangkan untuk memperoleh data, penelitian ini menggunakan metode penelitian kualitatif-deskriptif dengan pendekatan studi kasus (Case Study), dengan menggunakan metode observasi (pengamatan/observation), interview (wawancara), dan dokumentasi.

\section{B. Pembahasan}

\section{Penciptaan Suasana Religius di Sekolah}

Penciptaan berasal dari kata dasar cipta yang mendapatkan imbuhan pe dan an. Awalan pe dan akhiran an pada kata penciptaan memiliki makna yang bertalian dengan kata verbal me atau proses. ${ }^{13}$ Kata cipta dalam Kamus Besar Bahasa Indonesia (KBBI) ialah kemampuan pikir untuk mengadakan sesuatu yang baru, angan-angan yang kreatif. Sedangkan kata penciptaan ialah proses, cara atau perbuatan menciptakan. ${ }^{14}$ Sedangkan kata suasana ialah memiliki makna iklim atau keadaan. ${ }^{15}$

Kata religion (bahasa inggris), sama dengan religie (bahasa belanda), din (bahasa arab), dan agama (bahasa Indonesia). Kemudian baik religion dan religie, keduanya berasal dari kata latin relegere to treat carefully, relegere to bind together atau relegere to recover yang artinya mengumpulkan dan membaca. ${ }^{16}$ Sedangkan religius berarti bersifat religi atau keagamaan atau yang bersangkut paut dengan agama. ${ }^{17}$ Religius dapat dibagi menjadi dua kategori, yakni kepercayaan dan ritus. Yang pertama merupakan pendapat-pendapat (States of opinion), dan terdiri dari representasi-representasi. Yang kedua adalah bentuk-bentuk tindakan (action) yang khusus. Di antara dua kategori terdapat jurang yang memisahkan cara berfikir (thinking) dan cara berprilaku (doing). ${ }^{18}$

Adapun agama terdiri dari dua suku kata yaitu $a=$ tidak dan gam $=$ pergi, yang berarti mengandung arti tidak pergi, tetap di tempat atau diwarisi turun temurun. ${ }^{19}$ Menurut Spencer didalam buku yang dikarang

13 M. Iqbal Muttaqin, Pedoman Umum EYD dan Dasar Umum Pembentukan Istilah, (Jogjakarta: Diva Press, 2013), cet. Ke-4, hlm. 173.

Ke-3, hlm. 215.
15 Tim Prima Pena, Kamus Ilmiah Populer, (Surabaya: Gita Media Press, 2006), hlm. 448.

16 Ridjaluddin, Psikologi Islam "Jiwa Pemikiran Al-Ghazali dan keterkaitannya" Teori Psikologi Barat Modern. (Jakarta: Pustaka Kajian Islam FAI UHAMKA. 2009), Cet. Ke1,hlm. 79.

17 Depdikbud, Kamus Besar Bahasa Indonesia, 994.

18 Emile Durkheim, The Elementary Forms of The Religious Life, (Jogjakarta: IRCiSoD, 2011), hlm. 66.

19 Ridjaluddin, Psikologi Islam "Jiwa Pemikiran Al-Ghazali dan keterkaitannya" 
oleh Emile Durkheim mengatakan bahwa agama pada dasarnya adalah keyakinan akan adanya sesuatu yang maha kekal yang berada di luar intelek. ${ }^{20}$

Agama lebih menunjuk kepada kelembagaan atau kebaktian kepada Tuhan atau kepada dunia atas dalam aspeknya yang resmi, yuridis, peraturan-peraturan dan hukum-hukumnya serta keseluruhan organisasiorganisasi sosial keagamaan dan sebagainya yang melingkupi segi kemasyarakatan. ${ }^{21}$

Hal yang harus ditekankan di sini adalah bahwa religius itu tidak identik dengan agama. Semestinya orang yang beragama itu sekaligus orang yang religius. Misalnya seorang yang tekun beribadah secara kasat mata namun dibalik hal itu dia seorang penipu, ini bukan dinamakan manusia religius. Ada hal lain yang secara pandangan orang dia tidak begitu cermat ibadah namun dia memiliki kepekaan sosial yang tinggi, suka menolong, boleh jadi dia bukan manusia sempurna yang bisa di jadikan teladan akan tetapi dia manusia baik yang mempunyai antena religius. ${ }^{22}$

Dari serangkaian arti kata di atas, Prof. Dr. Muhaimin, M.A memberikan ulasan pengertian tentang penciptaan suasana religius di sekolah yakni penciptaan suasana atau iklim kehidupan keagamaan Islam yang dampaknya ialah berkembangnya suatu pandangan hidup yang bernafaskan atau dijiwai oleh ajaran dan nilai-nilai Islam yang diwujudkan oleh sikap hidup atau keterampilan hidup oleh warga sekolah. ${ }^{23}$

Berdasarkan hal tersebut budaya atau iklim religius di sekolah merupakan cara berfikir dan bertindak warga sekolah yang didasarkan atas nilai-nilai keberagamaan. Allah SWT berfirman dalam Al-Qur'an surah Al-Baqorah ayat 208:

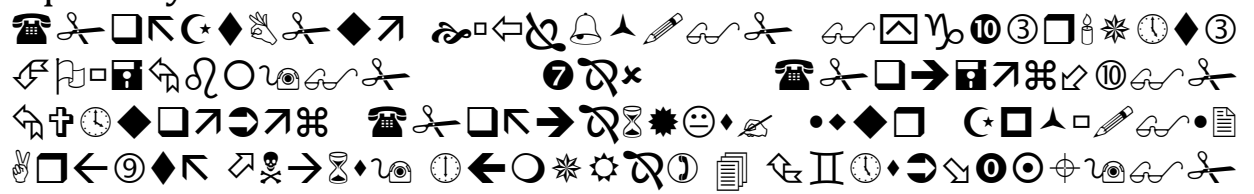

Teori Psikologi Barat Modern. (Jakarta: Pustaka Kajian Islam FAI UHAMKA. 2009), hlm. 79.

20 Emile Durkheim, The Elementary Forms of The Religious Life, hlm. 50.

21 Muhaimin et. al, Paradigma Pendidikan Islam: Upaya Mengefektifkan Pendidikan Agama di Sekolah, (Bandung: Remaja Rosdakarya, 2012), hlm. 287-288.

22 Muhammad Fathurrahman, Budaya Religius Dalam Peningkatan Mutu Pendidikan: Tinjauan Teoritik dan Praktik Konstektualisasi Pendidikan Agama di Sekolah, (Yogyakarta: Kalimedia, 2015), hlm. 51.

23 Muhaimin, Pengembangan Kurikulum Pendidikan Agama Islam di Sekolah. Madrasah dan Perguruan Tinggi, (Jakarta: PT Grafindo Persada, 2005), hlm. 61.

$236 \mid$ JURNAL LISAN AL-HAL 


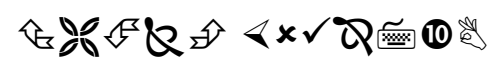

"Hai orang-orang yang beriman, masuklah kamu ke dalam Islam keseluruhan, dan janganlah kamu turut langkah-langkah syaitan. Sesungguhnya syaitan itu musuh yang nyata bagimu" (QS. al-Baqarah : 208). ${ }^{24}$

Keberagamaan (Religiusitas) tidak selalu identik dengan agama. Agama lebih menunjukkan kebaktian kepada Allah, dalam aspek yang resmi, yuridis, peraturan dan hukumnya. Sedangkan aspek religiusitas lebih melihat hati nurani. Oleh karena itu, religiusitas keislaman lebih mendalam daripada agama yang tampak. ${ }^{25}$

\section{Penerapan Penciptaan Suasana Religius di Sekolah}

Dalam konteks agama islam, hubungan manusia terbagi menjadi dua bagian, yang pertama hubungan manusia secara vertikal atau dengan kata lain hablum min Allah. Yang kedua hubungan manusia secara horizontal atau hablum min an-nas, dan juga termasuk di dalamnya hubungan manusia dengan lingkungan sekitarnya. ${ }^{26}$

Pertama, Hubungan Manusia Secara Vertikal. Manusia adalah homo religius (makhluk agamis) yang selalu membutuhkan kekuatan supranatural insani atau supranatural alami untuk menolongnya mencapai prestasi dan mempertahankan hidup. Manusia memang di titahkan lemah, karena kelemahannya itulah Tuhan memberikan karunianya berupa agama. ${ }^{27}$ Sebagaimana Allah berfirman dalam surat an-Nisa' ayat 28 sebagai berikut: ${ }^{28}$

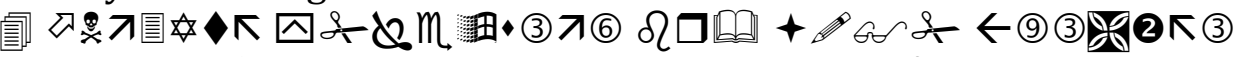

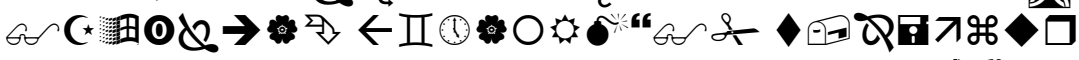

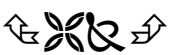

"Allah hendak memberikan keringanan kepadamu, ${ }^{29}$ dan manusia dijadikan bersifat lemah" (QS. An-Nisa': 28)

24 al- Qur'an, 2: 208.

25 Muhaimin et. al, Paradigma Pendidikan Islam: Upaya Mengefektifkan Pendidikan Agama di Sekolah, (Bandung: Remaja Rosdakarya, 2012), hlm. 288.

26 Muhaimin, 2005.Pengembangan Kurikulum Pendidikan Agama Islam di Sekolah. Madrasah dan Perguruan Tinggi, hlm. 61.

27 Sahilun A. Nasir. 1999, Peran Pendidikan Agama Terhadap Problem Pemecahah Remaja, (Jakarta: Kalam Mulia,1999), hlm. 124.

28 al-Qur'an, 4: 28

29 Yaitu dalam syari'at di antaranya boleh menikahi budak bila telah cukup syaratsyaratnya. 
Agama sebagai petunjuk hidup bagi manusia agar manusia menjalankan seluruh aktivitas hidupnya atas dasar ibadah dan pengabdian kepada Allah SWT, yang tertera dalam surat adz-Dzariyat ayat 56 berikut:

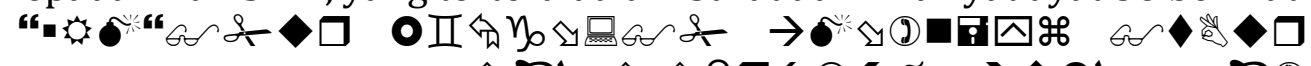

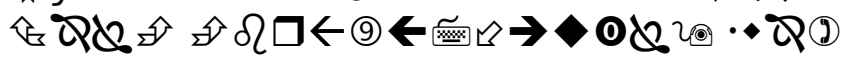

"Dan aku tidak menciptakan jin dan manusia melainkan supaya mereka mengabdi kepada-Ku". (QS. al-Dzariyat). ${ }^{30}$

Penciptaan suasana religius yang bersifat vertikal dapat diwujudkan dalam bentuk kegiatan-kegiatan ritual, seperti shalat berjama'ah, shalat dhuha, do'a bersama ketika dan setelah selesai belajar, dan sebagainya. Kegiatan ritual yang merupakan manifestasi dari hablum min Allah (vertikal) tersebut akan selalu memiliki konsekuensi horizontal dan sosial. ${ }^{31}$

Shalat dimulai dari takbiratul ihram (vertikal) dan diakhiri salam (horizontal), yang berarti ia memberikan kesejahteraan dan kedamaian kepada seluruh manusia, bahkan kepada seluruh alam semesta dan seisinya. Muhaimin dalam bukunya mengatakan jika seseorang hanya mementingkan hubungan ritual dengan Tuhannya dan kurang peduli terhadap hubungan sosial (horizontal), berarti ia lebih mementingkan keshalehan individu, dengan kata lain ia terjebak ke dalam hedonisme spiritual. 32

Penciptaan suasana religius di SMP Negeri 1 Asembagus secara vertikal dapat ditemukan diantaranya kegiatan do'a bersama yang dilaksanakan ketika akan memulai dan menutup pembelajaran. Pembacaan do'a dipimpin oleh utusan perkelas dengan menggunakan alat pengeras suara. Setelah selesai dilanjutkan dengan pembacaan surat-surat pendek, dan ditutup dengan menyanyikan lagu kebangsaan.

Selanjutnya di SMP Negeri 1 Asembagus juga menerapkan shalat dhuha, dan shalat dzuhur berjama'ah dengan dibimbing langsung oleh guru agama yang bertugas. Disamping itu biasanya guru BP juga membantu dalam pelaksanaannya, karena pembinaan sikap anak harus dengan pendekatan pembiasaan yang baik. Jadi guru BP tugasnya selain sebagai pembimbing juga sebagai teladan bagi para siswa.

Sesuai dengan yang disampaikan oleh Muhaimin bahwa untuk mewujudkan penciptaan suasana religius di sekolah, dapat dilakukan

30 al-Qur'an, 51: 56

31 Muhaimin, 2006. Nuansa Baru Pendidikan Islam: Mengurai Benang Kusut Dunia Pendidikan, hlm. 107.

32 Mementingkan kesalehan spiritual, lihat Muhaimin, 2006.Nuansa Baru Pendidikan Islam: Mengurai Benang Kusut Dunia Pendidikan, hlm. 108.

238 JURNAL LISAN AL-HAL 
melalui pendekatan pembiasaan, keteladanan, dan pendekatan persuasif atau mengajak kepada warga dengan cara halus dengan memberikan alasan dan prospek baik yang bisa meyakinkan mereka.

Kegiatan keagamaan yang berbentuk ekstrakurikuler atau yang dilaksanakan di luar jam sekolah ialah pesantren sekolah. Kegiatan ini dilaksanakan setiap hari kamis untuk kelas VII dan hari sabtu untuk kelas VIII, dengan fokus pada pembinaan baca tulis al-Qur'an, yang betujuan untuk meningkatkan bacaan al-Qur'an siswa.

Maka sebagai seorang pendidik, guru berkewajiban untuk menciptakan suasana religius di lingkungan belajar (sekolah). Penciptaan ini dimaksudkan dalam rangka mengimplementasikan nilai-nilai bersikap, nilai-nilai penghayatan dan menumbuhkan semangat kesadaran beragama.

Kedua, Hubungan Manusia Secara Horizontal. Selain penerapan penciptaan suasana religius secara vertikal, di SMP Negeri 1 Asembagus juga menerapkan secara horizontal yakni hubungan antar sesama warga sekolah maupun dengan lingkungan yang sekolah, diantaranya 3S yang dimulai sebelum memasuki halaman sekolah, kegiatan jum'at beramal yang dilakukan oleh seluruh siswa dan diprakarsai oleh Osis SMP Negeri 1 Asembagus dan hasilnya dialokasikan kepada yang terkena musibah, semisal kecelakaan, ada orang tuanya yang meninggal dan sebagainya.

Bagi para guru dan staf ialah kegiatan pemberian santunan kepada fakir miskin dan anak yatim piatu dengan memotong gaji guru pada setiap bulannya. Jadi seluruh warga sekolah bersinergi dalam melaksanakan pencitaan suasana religius.

Selanjutnya untuk hubungan yang terbina antar sesama warga sekolah, yakni hubungan atasan dengan bawahan, dengan sesama teman sebaya berjalan dengan harmonis. Siswa SMP Negeri 1 Asembagus bisa menjaga sikap yang sopan terhadap guru, begitu juga antar sesama guru saling terbina hubungan yang harmonis.

Hubungan warga sekolah dengan lingkungan terlihat bahwa di SMP Negeri 1 Asembagus sangat bersih, rapi dan nyaman, dan juga menerapkan lingkungan bebas plastik. Kebersihan dan kelestarian lingkungan, jadi tidak hanya menjadi tanggung jawab petugas kebersihan, melainkan menjadi tangung jawab seluruh warga sekolah.

Hal ini senada dengan yang dipaparkan oleh Nawawi dalam bukunya bahwa setidaknya ada empat tuntunan islam yang perlu di integrasikan dan di aktualisasikan dalam pendidikan lingkungan yaitu 
nilai pemeliharaan, nilai pelestarian, nilai pemanfaatan dan nilai keindahan. ${ }^{33}$

Menurut Muhaimin di dalam bukunya menjelaskan bahwa dalam konteks agama Islam, hubungan manusia terbagi menjadi dua bagian, yang pertama hubungan manusia secara vertical, yang kedua hubungan manusia secara horizontal dan juga termasuk di dalamnya hubungan manusia dengan lingkungan sekitarnya.

Dengan demikian, pendidikan agama di sekolah bukan hanya pada tataran kognitif saja, namun bagaimana membentuk kesadaran pada siswa untuk melaksanakan dan membudayakan nilai-nilai pendidikan agama dalam kehidupan sehari-hari.

Untuk mewujudkan penciptaan suasana religius di sekolah, dapat dilakukan melalui pendekatan pembiasaan, keteladanan, dan pendekatan persuasif atau mengajak kepada warga dengan cara halus dengan memberikan alasan dan prospek baik yang bisa meyakinkan mereka. ${ }^{34}$

Dengan pembiasaan nilai-nilai religius di sekolah diharapkan mampu meningkatkan dan memperkokoh nilai ketauhidan seseorang, pengetahuan agama dan praktik keagamaan. Proses internalisasi nilainilai agama ini akan terwujud jika dalam sekolah ada sebuah pembiasaan yang dilakukan oleh masyarakat sekolah. Dari pembiasaan yang dilakukan diharapkan akan membentuk karakter siswa yang religius.

\section{Simpulan}

Berdasarkan data yang diperoleh dari hasil penelitian yang telah peneliti paparkan serta analisa yang telah peneliti lakukan, maka dapat disimpulkan sebagai berikut: Pertama, penerapan penciptaan religius secara vertikal, yakni hubungan warga sekolah terhadap Tuhan YME, yang berbentuk berbagai kegiatan keagamaan seperti pembacaan do'a secara bersama yang dilaksanakan sebelum dan sesudah pembelajaran, shalat duha, shalat dzuhur berjama'ah. Selain itu, kegiatan keagamaan yang dilaksanakan di luar jam sekolah (ekstrakurikuler) yang bekerjasama dengan pondok pesantren Salafiyah Syafi'iyah Sukorejo yakni pesantren sekolah yang menfokuskan pada pembelajaran Al-Qur'an.

Kedua, penerapan penciptaan religius secara horizontal, yakni hubungan warga sekolah terhadap sesamanya yang harmonis antara

33 Nawawi, Islam Agama Solutatif dalam Menjawab Problem Sosial, (Jember: Pustaka Radja, 2014), hlm. 57.

34 Muhaimin, Nuansa Baru Pendidikan Islam: Mengurai Benang Kusut Dunia Pendidikan, 133.

$240 \mid$ JURNAL LISAN AL-HAL 
atasan-bawahan. Selain itu juga terdapat beberapa kegiatan, kegiatan tersebut diantaranya 3S yang dimulai sebelum memasuki halaman sekolah, kegiatan jum'at beramal yang dilakukan oleh seluruh siswa dan diprakarsai oleh Osis SMP Negeri 1 Asembagus dan hasilnya dialokasikan kepada yang terkena musibah, santunan terhadap fakir miskin dan yatim piatu yang dilakukan oleh jajaran kepala sekolah, staf beserta dewan guru. Serta kebersihan dan kelestarian lingkungan yang menjadi tanggungjawab bersama.

\section{DAFTAR PUSTAKA}

Arifi, Ahmad. Politik Pendidikan Islam: Menelisuri Ideologi dan Aktualisasi Pendidikan Islam di Tengah Arus Globalisasi, Yogyakarta: Teras, 2010.

Depdikbud, Kamus Besar Bahasa Indonesia, 994.

Depdikbud, Kamus Besar Bahasa Indonesia, Jakarta: Balai Pustaka, 2003.=

Durkheim, Emile. The Elementary Forms Of The Religious Life, Jogjakarta: IRCiSoD, 2011.

Fathurrahman, Muhammad. Budaya Religius Dalam Peningkatan Mutu Pendidikan: Tinjauan Teoritik dan Praktik Konstektualisasi Pendidikan Agama di Sekolah, Yogyakarta: Kalimedia, 2015.

Jawa Pos Radar Situbondo, Tanamkan Sikap Religius Melalui Pesantren Sekolah, (Sabtu, 28 November 2015.

Muhaimin et. al, Paradigma Pendidikan Islam: Upaya Mengefektifkan Pendidikan Agama di Sekolah, Bandung: Remaja Rosdakarya, 2012.

Muhaimin, Nuansa Baru Pendidikan Islam: Mengurai Benang Kusut Dunia Pendidikan, 2006.

Muhaimin, Pengembangan Kurikulum Pendidikan Agama Islam di Sekolah. Madrasah dan Perguruan Tinggi, Jakarta: PT Grafindo Persada, 2005.

Muttaqin, M. Iqbal. Pedoman Umum EYD dan Dasar Umum Pembentukan Istilah, Jogjakarta: Diva Press, 2013

Nasih, A. Munjin dan Lilik NK, Metodologi Pembelajaran Pendidikan Agama Islam, Malang: Cakrawala Indonesia, 2009.

Nasir, Sahilun. Peran Pendidikan Agama Terhadap Problem Pemecahah Remaja, Jakarta: Kalam Mulia,1999.

Nata, Abudin, Akhlak Tasawuf dan Karakter Mulia edisi revisi, Jakarta: Raja Grafinda Persada, 2013.

Nawawi, Islam Agama Solutatif dalam Menjawab Problem Sosial, Jember:

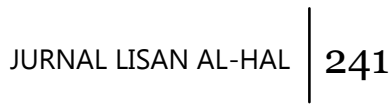


Pustaka Radja, 2014.

Ridjaluddin, Psikologi Islam "Jiwa Pemikiran Al-Ghazali dan keterkaitannya" Teori Psikologi Barat Modern. Jakarta: Pustaka Kajian Islam FAI UHAMKA. 2009.

Syah, Muhibbin, Psikologi Pendidikan Dengan Pendekatan Baru, Bandung: PT Remaja Rosdakarya, 2013.

Tim Prima Pena, Kamus Ilmiah Populer, Surabaya: Gita Media Press, 2006. Undang-Undang Republik Indonesia No.20 Tahun 2003 tentang Sistem Pendidikan Nasional, Jakarta: Sinar Grafika, 2008. 